\title{
Characterizing Antecedent Conditions Prior to Annual Maximum Flood Events in a High-Elevation Watershed Using Self-Organizing Maps
}

\author{
KATHLEEN D. HOLMAN \\ Bureau of Reclamation, Department of the Interior, Denver, Colorado
}

(Manuscript received 30 November 2017, in final form 3 July 2018)

\begin{abstract}
Flood frequency estimates are required for many water management and design engineering projects, including dam safety risk management activities. Most studies assume that annual or peak-over-threshold flood events are sampled from a single homogeneous population, an assumption that is sometimes invalid. In this study, we characterize conditions prior to annual maximum flood events in the Taylor Park watershed between water years 1981 and 2016 using historical observations and the self-organizing maps (SOM) algorithm. Inputs to the SOM algorithm include annual maximum daily reservoir inflow, annual maximum snow water equivalent (SWE), SWE melt length, and 4-day antecedent precipitation. Four-day antecedent precipitation is defined as the precipitation accumulated over the 3 days prior to and on the day of the annual maximum event. Results based on a $2 \times 2 \mathrm{SOM}$ output map, which represents four flood categories, suggest that $58 \%$ of events are the result of snowmelt with a near-negligible contribution from antecedent precipitation, $17 \%$ of events are the result of snowmelt combined with large antecedent precipitation, and the remaining $25 \%$ of events are the result of snowmelt with no contribution from antecedent precipitation. These results, which highlight the existence of more than one flood mechanism, may have implications for future flood frequency analyses in this watershed and other watersheds within the region.
\end{abstract}

\section{Introduction}

Flood frequency estimates are required for many water management and design engineering programs, such as water delivery canals, floodplain and stormwater management, and infrastructure, including bridges, dams, locks, and power facilities (Alila and Mtiraoui 2002). Conventional methods used to develop annual and peak-over-threshold flood frequency estimates, such as fitting a lognormal or log Pearson type III distribution to a time series, are often based on the assumption that all floods are randomly drawn from a single homogeneous population (Beard 1974; Adamowski 2000; Loukas et al. 2000). However, studies suggest that this assumption is not always valid, particularly in regions of complex topography, such as the Cascade Mountains (Waylen and Woo 1982), Colorado Front Range (Jarrett and Costa 1988), and Sierra Nevada region of California (Parrett et al. 2011). Research suggests that the assumption that annual maximum flood events are independent and identically distributed can be invalid because the hydroclimate is not statistically "static" at all time scales, and

Corresponding author: Kathleen Holman, kholman@usbr.gov the risk of a flood of a given magnitude varies from one year to the next (Pui et al. 2011; Lee and Jeong 2014; Franks et al. 2015). Erroneously assuming that all flood events have been sampled from a single homogeneous population can have implications on flood frequency estimates (Elliott et al. 1982; Waylen and Caviedes 1990; Alila and Mtiraoui 2002; Andrews et al. 2004). Consequently, understanding the antecedent conditions and physical mechanisms responsible for flood events may help improve flood frequency estimates and aid in decision-making processes (Alila and Mtiraoui 2002; Sikorska et al. 2015).

The physical interactions that result in a flood of a given probability are controlled by a number of different processes, including flood-producing mechanisms (e.g., frontal systems, thunderstorms, snowmelt), low-frequency climate variability (e.g., El Niño-Southern Oscillation, Pacific decadal oscillation), variations in watershed conditions, and channel and floodplain morphology (Jain and Lall 2000; Alila and Mtiraoui 2002; Merz and Blöschl 2003). Some studies utilize time of year as a metric for flood mechanisms (Burn 1997; Pizarro and Lall 2002; Sivandran 2002; De Michele and Rosso 2002; Todhunter 2012). However, using flood seasonality as a metric for a 


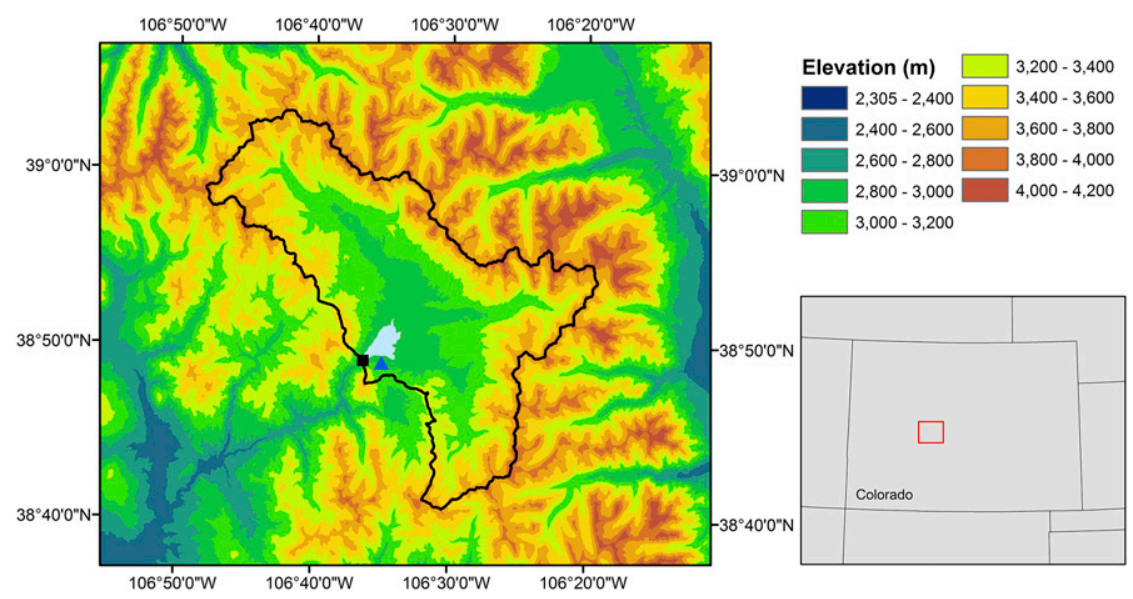

FIG. 1. Location and elevation surrounding the Taylor Park watershed (black polygon) in western-central Colorado. The light blue polygon inside the watershed represents the extent of Taylor Park Reservoir $\left(8.26 \mathrm{~km}^{2}\right.$ at full capacity). The black square represents the location of Taylor Park Dam $\left(38.8186^{\circ} \mathrm{N}, 106.6058^{\circ} \mathrm{W}\right)$. The blue triangle represents the location of the Park Cone station $\left(38.8167^{\circ} \mathrm{N}, 106.5833^{\circ} \mathrm{W}\right)$

mechanism can be problematic in watersheds where multiple processes act during the same time of year (Gupta et al. 1976), such as in high-elevation watersheds that are influenced by both snowmelt and rain-on-snow events.

Other studies develop methods for identifying flood mechanisms in regions influenced by mixed processes. For example, Waylen and Woo (1982) use 4-day total antecedent precipitation and surface temperature to identify the physical mechanisms of annual maximum floods in the Coquihalla River watershed in the Cascade Mountains between 1912 and 1980. The authors use an antecedent precipitation threshold of $25 \mathrm{~mm}$ to categorize annual maximum events as precipitation- (greater than $25 \mathrm{~mm}$ ) or snowmelt-driven (less than $25 \mathrm{~mm}$ ). Sui and Koehler (2001) use observed snow water equivalent (SWE) to stratify the largest flood events on record into rainfall and combined rain and snowmelt floods in a forest watershed located in southern Germany. Merz and Blöschl (2003) use flood timing, precipitation duration and depth, snowmelt, catchment state, runoff response, and spatial coherence to classify flood mechanisms in 490 watersheds across Austria into five flood types. Those types include long-rain floods, short-rain floods, flash floods, rain-on-snow floods, and snowmelt floods. Rather than developing strict criteria and thresholds, the authors visually inspect conditions during each flood event on record and manually categorize each event. Their results indicate that long-rain floods are the most common type of annual maximum floods in Austria ( $43 \%$ of events), while snowmelt-driven events are the least common ( $3 \%$ of events).

Some investigations broaden the analysis of historical flood mechanisms beyond surface conditions
(Hirschboeck 1987; Kim et al. 2010; Stucki et al. 2012; Nakamura et al. 2013). For example, Hirschboeck (1987) uses season of flood occurrence, surface pressure, geopotential height, and the spatial distribution of precipitation within a decision-tree framework to categorize floods by mechanism in the Gila River watershed in Arizona. The mechanisms include tropical storm, cutoff low, front (or monsoon front), monsoon widespread precipitation, monsoon localized precipitation, widespread precipitation, localized precipitation, and snowmelt. The author computes flood frequency estimates for each subgroup using rather small population sizes. Results suggest that the parameters used to describe flood frequencies (e.g., means, variances, and shapes) may be dependent on the flood-producing mechanism. More recently, Nakamura et al. (2013) investigate atmospheric circulation conditions that are associated with extreme spring (March-May) flooding events in the Ohio River basin between 1901 and 2008. Their results suggest that low-level moisture divergence from the tropical Atlantic, a climatological feature, is common to these spring flooding events.

While previous studies emphasize mixed processes across domains under variable climatic influences (e.g., Merz and Blöschl 2003), we explore antecedent conditions prior to annual maximum flood events in a relatively small, undeveloped watershed located in west-central Colorado, the Taylor Park watershed (Fig. 1). We classify annual maximum flood events using historical surface observations in conjunction with the self-organizing maps (SOM) algorithm (Kohonen 1990), an objective, nonlinear neural network algorithm. The SOM algorithm has been used successfully in a number of scientific and 
engineering applications (Chang et al. 2007; Srinivas et al. 2008; Farsadnia et al. 2014). However, the SOM algorithm has yet to be used as an objective method for characterizing antecedent conditions prior to annual flood events. The objective of this paper is to examine antecedent conditions prior to annual maximum flow events in the Taylor Park watershed in an effort to answer the question, are these annual maximum flood events the result of one or more flood mechanisms? Findings from this study, along with the methods presented herein, can be combined with existing flood frequency methods documented in the literature for the purpose of developing flood frequency estimates in the presence of clearly defined mixed populations.

\section{Data and methods}

The area of interest in this study is the Taylor Park watershed, a headwater of the Colorado River located in west-central Colorado. The Taylor River begins on the western flank of the Sawatch Mountains and flows into Taylor Park Reservoir, which is impounded by Taylor Park Dam. The dam controls runoff from an area of $657.9 \mathrm{~km}^{2}\left(254 \mathrm{mi}^{2}\right)$ and is owned and operated by the Bureau of Reclamation as part of the Uncompahgre Project (Clark 1994). At full capacity, the surface area of Taylor Park Reservoir is $8.3 \mathrm{~km}^{2}$ (2040 acres), with a maximum volume of $0.1 \mathrm{~km}^{3}$ (104253 acre feet). Average elevation of the watershed is $3314.5 \mathrm{~m}(10874.3 \mathrm{ft})$, with a maximum elevation of $4249.6 \mathrm{~m}(13942.3 \mathrm{ft})$ and minimum elevation of $2819.3 \mathrm{~m}(9249.7 \mathrm{ft})$. According to the 2011 National Land Cover Database (Homer et al. 2015 ), almost $55 \%$ of the watershed is evergreen forest, $25 \%$ is herbaceous, and $11 \%$ is barren. Outflow from Taylor Park Reservoir flows into the Gunnison River, which accounts for $40 \%$ of the flow of the Colorado River at the Utah-Colorado border (McCabe and Hay 1995).

In an effort to characterize conditions prior to annual maximum flood events, we explore historical surface observations of daily precipitation and SWE in the watershed. Daily precipitation observations are available through the Global Historical Climatology Network (GHCN; Menne et al. 2012). We analyze records from the Park Cone station (ID: USS0006L02S), which is located in the watershed $\left(38.8167^{\circ} \mathrm{N}, 106.5833^{\circ} \mathrm{W}\right.$, $2926.1 \mathrm{~m}$ MSL; Fig. 1) and has daily records that extend from 1 August 1980 to present. Daily SWE records are also available at the Park Cone station over the same time period. We also analyze daily inflow to the Taylor Park Reservoir. This variable is computed by the $\mathrm{Bu}-$ reau of Reclamation's Upper Colorado River Office. We analyze computed inflow instead of streamflow observations in the watershed because of data continuity and period of record; the computed inflow time series is continuous at a daily time step from 1 October 1962 to present. Historical streamflow observations in the watershed are available from two U.S. Geological Survey gauges, Taylor Park (ID: 09107000) and Texas Creek (ID: 09107500). However, neither gauge captures flow from the entire watershed, and neither gauge includes continuous observations during the period of available observations from the Park Cone station (precipitation and SWE). We compared computed daily reservoir inflow to streamflow observations during periods of overlapping records (not shown). The correlation coefficient between computed inflow and observed flow at the Taylor Park (Texas Creek) gauge is 0.97 (0.91). A monthly correlation analysis showed that the computed and observed flow series have the strongest relationship during some peak flow months, such as May and June, albeit with very different flow magnitudes due to differences in representative area. Consequently, we focus our analysis on computed daily reservoir inflow. All results presented are valid over the period when precipitation, SWE, and computed daily inflow are available, specifically water years (WY) 1981-2016.

We classify antecedent conditions prior to annual maximum flood events using the SOM algorithm, an unsupervised and competitive learning algorithm commonly used to analyze, cluster, model, and predict relationships among large datasets. The SOM algorithm learns to cluster groups of similar input patterns from high dimensional input onto a low dimensional discrete lattice of neurons in an output layer (Kalteh et al. 2008). The algorithm clusters inputs into a predefined number of classes and orders those classes in a meaningful way in the output layer. Output neurons have the same dimensionality as the input data. The three steps required to run the SOM algorithm include data gathering and normalization, training, and plotting results from the trained SOM. Data normalization is used to prevent certain input variables from receiving greater weight during the training process. Kalteh et al. (2008) suggest normalizing variables to a range from zero to one. Data training involves initializing weight vectors (which have the same dimension as the input data) using random or linear initialization. The SOM algorithm iterates through each input vector and matches it with a neuron of the SOM output map using some objective criteria, typically Euclidean distance. The neuron with the closest match, or lowest Euclidean distance between the output neuron and input vector, is called the winning neuron or best matching unit. The winning neuron and neighboring neurons are updated; neighboring neurons are updated with a neighborhood function. The final step of the SOM analysis is presentation of results. 
Alternative clustering methods exist, such as the $k$-means clustering algorithm (Hartigan and Wong 1979; Likas et al. 2003). The $k$-means algorithm identifies $k$ clusters and maps each input variable to a cluster according to the Euclidean distance from the mean such that the variance within each cluster is minimized. This aspect of the algorithm makes it suitable for applications when the variable of interest follows a mixture of normal distributions. However, caution must be taken when applying the $k$-means algorithm to variables that are not normally distributed or mixtures of normal distributions (Bernard et al. 2013). Alternatively, the SOM algorithm can classify nonlinear, high-dimensional data to some user-defined lower dimension. The nonparametric SOM algorithm is capable of processing large amounts of discrete and continuous data, while avoiding the assumption of normal distributed required by other techniques, such as the $k$-means algorithm (Besaw et al. 2009). Furthermore, the neighborhood function of the SOM algorithm acts to place nodes with similar features near one another (while at the same time placing dissimilar nodes away from one another), such that the output node placements are indicative of similar nodes. The $k$-means clustering algorithm does not order output nodes in a similar fashion. We implement the SOM algorithm instead of the $k$-means clustering algorithm because of the nonparametric assumptions and the more sophisticated output layout (Smith and $\mathrm{Ng}$ 2003).

We apply the SOM algorithm to a set of annual observations between WY 1981 and 2016, including annual maximum daily inflow, annual maximum SWE, SWE melt length, and 4-day antecedent precipitation. We use input variables to the SOM algorithm that describe local precipitation and SWE conditions prior to and during historical flood events. Annual maximum SWE is defined as the largest recorded value of SWE in a given WY. Melt length is defined as the number of days between the maximum SWE observation and the first date of zero SWE after the annual maximum. Four-day antecedent precipitation is computed as the sum of precipitation from each of the 3 days prior to and on the day of the annual maximum daily inflow event (for a total of four days). Each variable is normalized prior to input in the SOM algorithm by dividing all entries by the maximum value among years (i.e., all 4-day precipitation totals are divided by the maximum 4-day precipitation total). There is no published guidance on how to specify the dimensions of the SOM output map (Lin and Chen 2006). Consequently, we assume a $2 \times 2$ SOM output map, which is smaller than many previous applications, in an effort to distinguish antecedent conditions while maintaining a reasonable number of flood events in each SOM group. We utilize random initialization for the output nodes, assume a Gaussian neighborhood function, and perform 5000000 iterations during training.

The current application of the SOM algorithm is designed to cluster annual maximum flood events in the Taylor Park watershed into four groups based on the behavior of annual maximum inflow, annual maximum SWE, SWE melt length, and 4-day antecedent precipitation prior to and during the annual maximum flood events. We utilize these input variables because they represent hydrometeorological conditions within the watershed, and they capture the complex interactions that result in annual maximum flows. Each year maps to a single output node (one of the four), and we consider all years that map to a given output node as generated by the same flood mechanism. We characterize flood mechanisms by evaluating average hydrometeorological conditions during the years that map to each node.

\section{Watershed hydroclimate}

Figure 2 shows historical observations of daily inflow to the Taylor Park Reservoir, monthly total precipitation, and daily SWE between WY 1981 and 2016 in the form of box-and-whisker plots. Daily flows in this watershed are characterized by a strong seasonal cycle (Fig. 2a). Inflows are typically highest in June; May and July have the next highest inflows, respectively. Average inflows into the reservoir during the remainder of the year (AugustApril) are relatively low, less than $5 \mathrm{~m}^{3} \mathrm{~s}^{-1}\left(177 \mathrm{ft}^{3} \mathrm{~s}^{-1}\right)$. Unlike daily inflows, average monthly precipitation in the watershed shows a relatively weak seasonal cycle (Fig. 2b). Average monthly totals range from $23 \mathrm{~mm}$ (0.9 in.) in June to $56 \mathrm{~mm}$ (2.2 in.) in December. On average, daily SWE at the Park Cone station begins accumulating during late fall (October; Fig. 2c). Daily SWE typically peaks during March and April, with large declines (on average) from April to May. Between June and September, average daily SWE at the Park Cone station is zero. These observations show that, on average, monthly total precipitation is lowest during the month with the largest average daily inflows, June. Average daily inflows to the reservoir increase from April through June, though average monthly total precipitation declines. An alternative source of water for late spring and early summer flows is snowpack. SWE typically declines from April to June, suggesting that this variable plays an important role in generating peak inflows.

\section{Results}

Figure 3 shows the time series of annual maximum daily inflow into the reservoir between WY 1981 and 2016. Historical annual maximum daily inflow events 

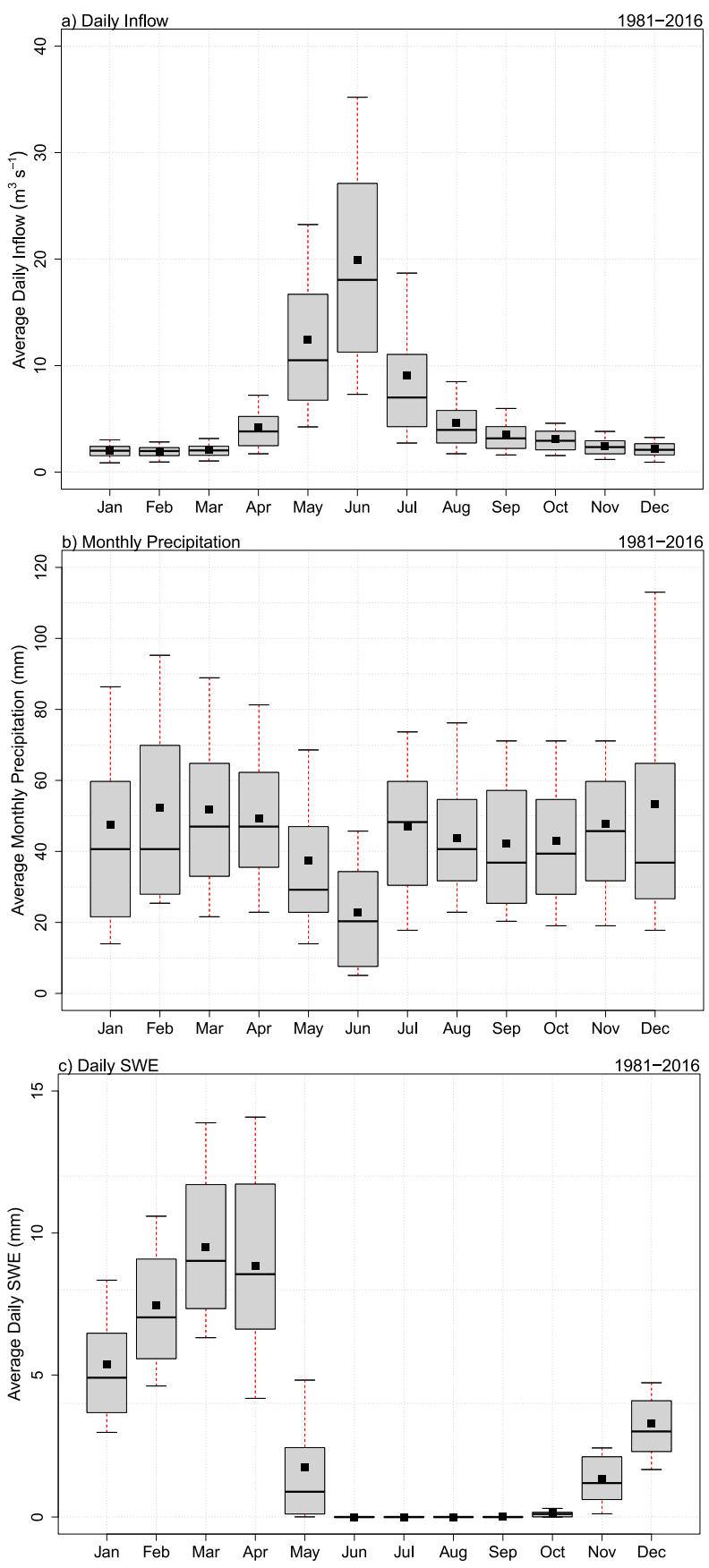

FIG. 2. Box-and-whisker plot of (a) average daily reservoir inflow $\left(\mathrm{m}^{3} \mathrm{~s}^{-1}\right),(\mathrm{b})$ monthly total precipitation $(\mathrm{mm})$, and (c) daily SWE $(\mathrm{mm})$, by month between WY 1981 and 2016. The red dashed lines extend to the 10th and 90th percentiles. The black squares represent the average. The middle horizontal black lines of the boxes represent the median value. The horizontal bounding lines of the boxes represent the 25 th and 75 th percentiles. Precipitation and SWE observations are based on records from the Park Cone station. have all occurred during the months of May-July. The largest (lowest) annual maximum daily inflow event on record occurred on 18 June 1995 (20 May 2002). Frequency results from the SOM analysis applied to annual maximum daily inflow, annual maximum SWE, melt length, and 4-day antecedent precipitation are shown in the inset of Fig. 3. This $2 \times 2$ output map shows the number of years that map to each SOM node. Nodes 1-4 describe 14, 7, 6, and 9 years, respectively. The symbol color of annual maximum daily inflow values in Fig. 3 represents the SOM node to which each year maps. These colors indicate that most of the maximum flow values in groups 1 and 2 are near or below the long-term average value. Conversely, maximum flow values from groups 3 and 4 are nearly all at or above the long-term average. Thus, events with above-average flow conditions map to two different SOM groups and result from two different flood-generating mechanisms, similar to below-average flow events.

Results in Fig. 4 show the relationship between annual maximum daily inflow and each of the SOM training variables (e.g., annual maximum SWE, melt length, and 4-day antecedent precipitation), with records from each annual event colored by SOM group. Data in Fig. 4a show the relationship between annual maximum inflow and annual maximum SWE. The two variables are positively correlated with a correlation coefficient of 0.68 , indicating that approximately $82 \%$ of the variance in annual maximum inflow is explained by annual maximum SWE at the Park Cone station. In addition, results in Fig. 4a demonstrate that annual maximum SWE in groups 3 and 4 is generally larger than observations from groups 1 and 2. Maximum SWE values in groups 1 and 2 do not exceed $290 \mathrm{~mm}$ (11.4 in.), while maximum SWE values in groups 3 and 4 reach $450 \mathrm{~mm}$ (17.7 in.). Figure $4 \mathrm{~b}$ shows the distribution of melt length among SOM groups, as well as the relationship between annual maximum inflow and melt length. Years in group 1 have some of the shortest melt lengths considered in the analysis, while years in group 4 have some of the longest melt lengths. A positive relationship between annual maximum SWE and melt length exists at this location, where larger annual maximum SWE values are associated with longer melt times. Consequently, the relationship between annual maximum inflow and melt length in Fig. $4 \mathrm{~b}$ is indirectly related to maximum SWE. Results in Fig. 4c show the relationship between annual maximum inflow and 4-day antecedent precipitation. Groups 1 and 2 have four and two events with nonzero 4-day antecedent precipitation, respectively; however, those precipitation totals are all less than $8 \mathrm{~mm}$ ( $0.3 \mathrm{in}$.). Every year that maps to group 3 is characterized by 4 -day antecedent precipitation totals 


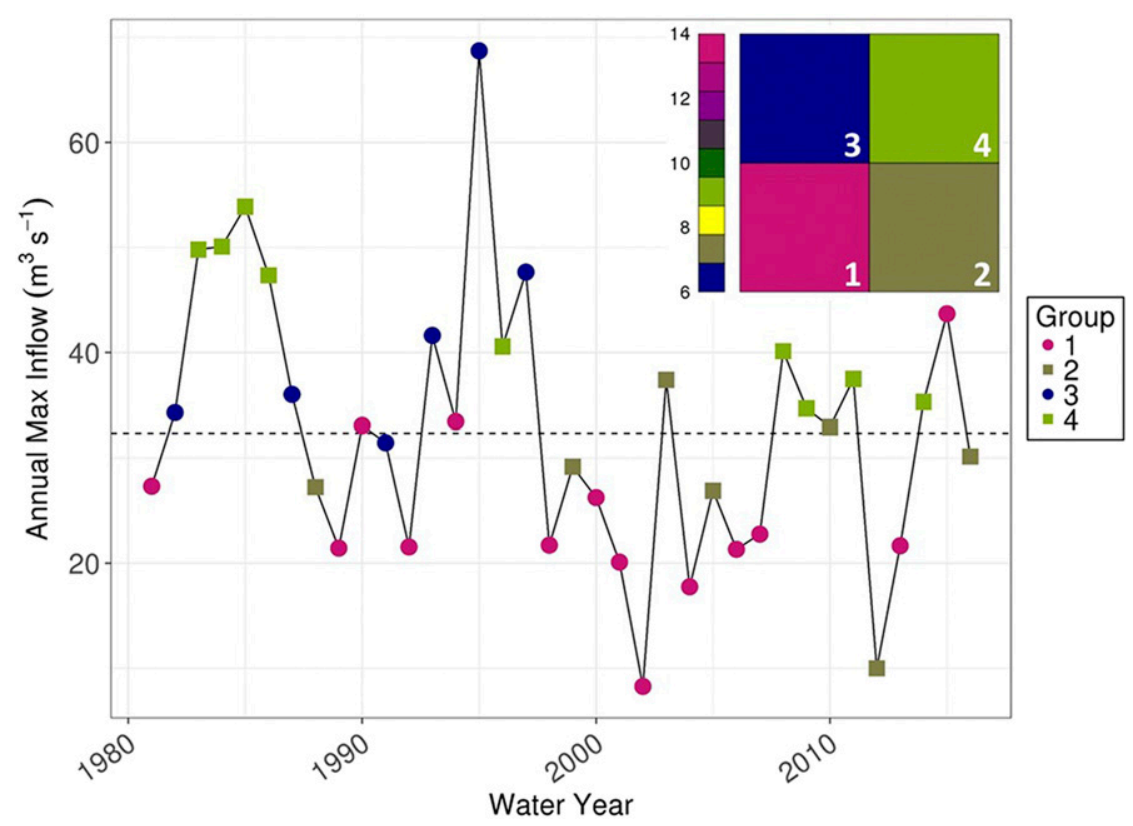

FIG. 3. Annual maximum average daily reservoir inflow $\left(\mathrm{m}^{3} \mathrm{~s}^{-1}\right)$ between 1981 and 2016. The dashed horizontal line indicates the long-term average daily reservoir inflow $\left(\mathrm{m}^{3} \mathrm{~s}^{-1}\right)$ for the same time period. The symbol color indicates the SOM group to which the year is mapped. The inset shows the SOM output map, where the color indicates the number of years that map to each node. The white integers on the SOM output map indicate group number.

greater than $12 \mathrm{~mm}(0.47 \mathrm{in}$.). Conversely, every year that maps to group 4 has zero 4 -day antecedent precipitation.

Figure 5 shows annual maximum daily inflow, annual maximum SWE, melt length, and 4-day antecedent precipitation averaged over all the years in each of the four SOM groups. Average annual maximum daily inflows (Fig. 5a) in groups 1 and 2 are less than the average values from groups 3 and 4, consistent with the results in Fig. 3. Furthermore, the average annual maximum daily inflows in groups 3 and 4 are essentially identical (approximately $43 \mathrm{~m}^{3} \mathrm{~s}^{-1}$ ), as events in these groups represent some of the largest annual maximum inflow events recorded during this time. Average annual maximum SWE conditions (Fig. 5b) mimic the average maximum daily inflow conditions in Fig. 5a; groups 1 and 2 have similar maximum SWE totals to each other, yet lower average annual maximum SWE totals than groups 3 and 4. Average melt length (Fig. 5c) is lowest for group 1 , the group with the lowest average annual maximum inflow, and greatest for group 4 . While groups 1 and 2 are both characterized by relatively low average maximum daily inflows and low average maximum SWE, the two groups differ in the average melt length; group 1 has the lowest average melt length among all groups. Average 4-day antecedent precipitation (Fig. 5d) is nearly zero for groups 1 and 2, largest for group 3, and zero for group 4 . The average 4-day antecedent precipitation for group 3 is almost $17 \mathrm{~mm}$ (0.66 in.), while the average 4-day antecedent precipitation for group 4 is zero. Clearly, 4-day antecedent precipitation is the distinguishing characteristic between events in group 3 and events in group 4, the two groups with the largest average annual maximum daily inflow. Results in Fig. 5 show that annual maximum flood events in groups 1,2 , and 4 are primarily (if not entirely) driven by snowmelt. Conversely, the annual maximum flood events in group 3 are driven by snowmelt combined with antecedent precipitation. These results also indicate that the largest annual maximum inflow events in the watershed, events in groups 3 and 4, are the result of two different processes, namely, snowmelt with antecedent precipitation and strictly snowmelt, respectively.

In an effort to demonstrate the influence of mechanism on flood magnitudes, we plot historical annual maximum daily inflows as a function of nonexceedance probability. Empirical nonexceedance probabilities are estimated for each annual event between 1981 and 2016 using the Weibull plotting position (Interagency Advisory Committee on Water Data 1982). The Weibull plotting position $P_{i}$ of a given observation $i$ is computed by dividing the rank of the observation $R_{i}$ (highest to lowest) by the total number of observations $N$ plus one, such that $P_{i}=R_{i} /(N+1)$. Results are shown in Fig. 6. Events in groups 1 and 2, the snowmelt 

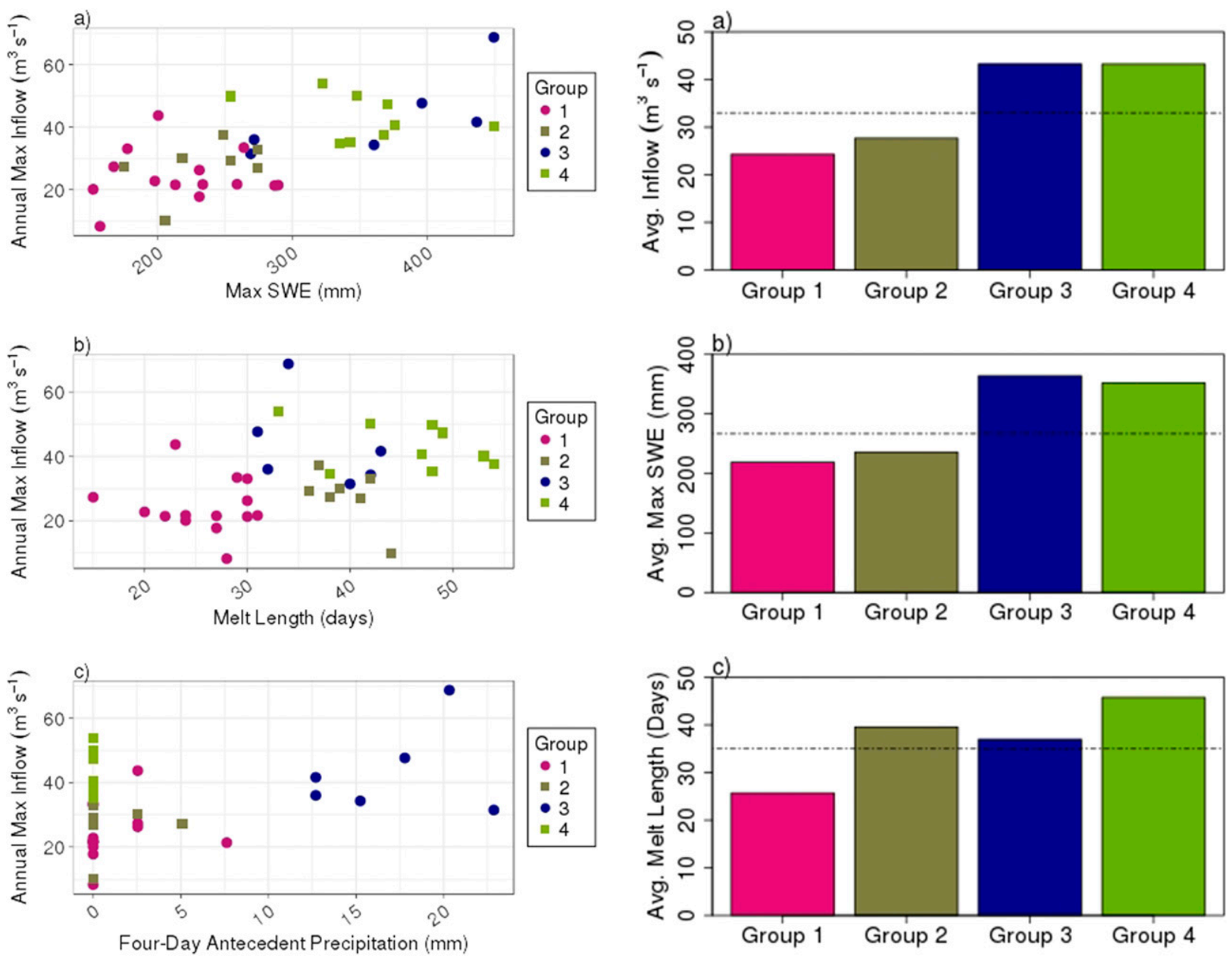

FIG. 4. Scatterplot showing the relationship between annual maximum average daily reservoir inflow $\left(\mathrm{m}^{3} \mathrm{~s}^{-1}\right)$ and (a) annual maximum SWE (mm), (b) melt length (days), and (c) 4-day antecedent precipitation (mm), between 1981 and 2016. The symbol color indicates the SOM group to which each year is mapped.

events with negligible antecedent precipitation, dominate nonexceedance probabilities less than 0.4. Conversely, events in groups 3 and 4 , the snowmelt with antecedent precipitation and strictly snowmelt events, respectively, dominate nonexceedance probabilities greater than 0.83 . Events from all groups occur at nonexceedance probabilities between 0.4 and 0.83 . This analysis illustrates the fact that floods with the greatest nonexceedance probabilities have resulted from two different mechanisms, a result that likely holds for neighboring watersheds simultaneously impacted by snowmelt and precipitation, as well. These results also show that various ranges of the nonexceedance probability curve are dominated by events produced by different mechanisms, a result that has ramifications for flood frequency estimates (Alila and Mtiraoui 2002).

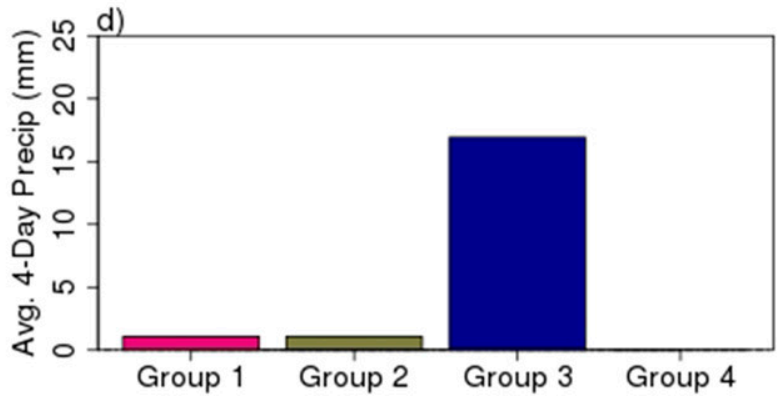

FIG. 5. (a) Annual maximum average daily reservoir inflow $\left(\mathrm{m}^{3} \mathrm{~s}^{-1}\right)$, (b) annual maximum SWE (mm), (c) melt length (days), and (d) 4-day antecedent precipitation $(\mathrm{mm})$ averaged over all years in each SOM group separately. The dashed horizontal line represents the median of all observations. The median 4-day antecedent precipitation is zero.

\section{Discussion and conclusions}

In this study, we explore and categorize annual maximum daily inflow events to the Taylor Park Reservoir based on antecedent surface conditions prior to these events. Annual maximum daily inflow events between 


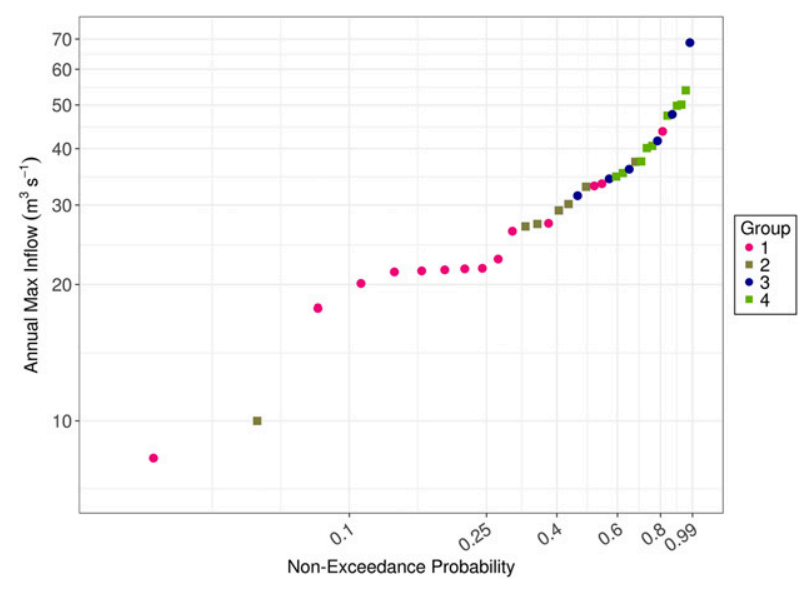

FIG. 6. Annual maximum daily inflow $\left(\mathrm{m}^{3} \mathrm{~s}^{-1}\right)$ into the Taylor Park Reservoir plotted as a function of nonexceedance probability. The symbol color indicates the SOM group to which each year is mapped.

WY 1981 and 2016 occurred exclusively during MayJuly, a time of year when average monthly precipitation is typically lowest and average monthly SWE is declining. We use an artificial neural network, specifically the SOM algorithm, to categorize antecedent conditions. Inputs to the SOM algorithm include annual maximum daily inflow, annual maximum SWE, SWE melt length, and 4-day antecedent precipitation. We utilize a $2 \times 2$ SOM output grid and categorize flood events into four categories. SOM groups 1-4 map to 14, 7, 6, and 9 years, respectively. Group 1 and 2 events are considered primarily snowmelt-driven events, because very few years have nonzero 4-day antecedent precipitation, and those years with antecedent precipitation have negligible totals. Group 3 events, which have the largest and all nonzero 4-day antecedent precipitation totals, are considered snowmelt events with antecedent precipitation. Finally, group 4 events are considered strictly snowmelt events, as all the years in this group have zero 4-day antecedent precipitation. Thus, $58 \%$ of events are the result of snowmelt with a negligible contribution from antecedent precipitation, $17 \%$ of events are the result of snowmelt with antecedent precipitation, and the remaining $25 \%$ of events are the result of strictly snowmelt with no contribution from antecedent precipitation. The analysis of nonexceedance probabilities demonstrates that flood events with the largest magnitudes and consequently largest nonexceedance probabilities are associated with two different mechanisms, snowmelt and snowmelt with antecedent precipitation, a result that likely has implications for future flood frequency estimates and may influence risk-based decisions in the watershed.

This work demonstrates the usefulness of the SOM algorithm for categorizing antecedent conditions prior to annual maximum flow events. However, certain aspects of the algorithm warrant further discussion. First, there is no official guidance on how to specify the dimensions of the SOM output map (Lin and Chen 2006); the choice is left up to the user. We define a $2 \times 2 \mathrm{SOM}$ output map in an effort to allow for multiple flood categories while also maintaining a reasonable sample population size in each group. Some group population sizes are still low, a result that has happened in previous flood characterization studies (e.g., Hirschboeck 1987). Nevertheless, increasing the dimensions of the SOM output map (e.g., $2 \times 3,3 \times 3$ ) resulted in some groups having very few to zero events (not shown). Zero-entry output nodes do not invalidate SOM results. In fact, increasing the dimensions of the SOM output node such that there are zero-entry nodes may be desirable in some applications (e.g., Lin and Chen 2006). However, in the current analysis, we focus on results from a $2 \times 2$ grid in order to broadly categorize events on record without isolating any single one (or few) event. Second, the SOM algorithm has added benefits over previous approaches used to categorize annual maximum flood events. The SOM algorithm eliminates the need for subjective (e.g., Waylen and Woo 1982) or visual-inspection-based (e.g., Merz and Blöschl 2003) criteria for categorizing flood events, a feature that is particularly useful for analyzing large population sizes, large numbers of forcing variables, or for classifying nonnormally distributed forcing variables (e.g., precipitation). In the absence of strict thresholds, the algorithm is able to identify distinctly different flood categories, including purely snowmelt events and snowmelt events with antecedent precipitation. There was no need to manually define criteria for annual maximum SWE totals, melt length duration, and/or 4-day antecedent precipitation totals.

Previous studies use month or season of occurrence as a metric for flood mechanism (e.g., Pizarro and Lall 2002). In the Taylor Park watershed, the focus of this study, all annual maximum flood events between WY 1981 and 2016 occurred between the months of May and July, yet the events resulted from different processes. Thus, using season of occurrence or time of year as the sole metric for flood mechanism would be insufficient at this high-elevation location, a finding that likely holds true for other watersheds where precipitation and snowmelt act simultaneously. Research by Hirschboeck (1987) and Alila and Mtiraoui (2002), among others, demonstrates the implications of erroneously assuming a single homogeneous distribution when fitting probability distributions to annual maximum flood events composed of mixed populations. The current study exposes the existence of multiple mechanisms in this watershed. Consequently, neglecting to separate pure snowmelt events 
from snowmelt with antecedent precipitation events in future flood frequency studies could result in an underestimation of the flood hazard. Though outside the scope of the current study, future research will focus on applying the SOM algorithm to flood categorization over a large number of watersheds with differing hydroclimates and flood-generating mechanisms. Additional input variables of potential interest for future work include surface air temperature, soil moisture, and evaporation.

Acknowledgments. This research was funded by the Bureau of Reclamation's Dam Safety Technology Development Program, under the work order identification CFTYL and CFTY2. Computed inflows to Taylor Park Reservoir are available at https://water.usbr.gov/query. php?sites = taylorpark. Analysis was conducted using the freely-available software, $\mathrm{R}$ language ( $\mathrm{R}$ Core Team 2017). The author would like to thank two anonymous reviewers for their constructive comments and helpful suggestions. The author would also like to thank Keil Neff.

\section{REFERENCES}

Adamowski, K., 2000: Regional analysis of annual maximum and partial duration flood data by nonparametric and L-moment methods. J. Hydrol., 229, 219-231, https://doi.org/10.1016/ S0022-1694(00)00156-6.

Alila, Y., and A. Mtiraoui, 2002: Implications of heterogeneous flood-frequency distributions on traditional stream-discharge prediction techniques. Hydrol. Processes, 16, 1065-1084, https:// doi.org/10.1002/hyp.346.

Andrews, E., R. C. Antweiler, P. J. Neiman, and F. M. Ralph, 2004: Influence of ENSO on flood frequency along the California coast. J. Climate, 17, 337-348, https://doi.org/10.1175/15200442(2004)017<0337:IOEOFF $>2.0 . \mathrm{CO} ; 2$.

Beard, L. R., 1974: Flood flow frequency techniques. Guidelines for determining flood flow frequency, Bulletin 17B of the Hydrology Subcommittee, Interagency Advisory Committee on Water Data, 14-1-14-35, https://water.usgs.gov/osw/ bulletin17b/dl_flow.pdf.

Bernard, E., P. Naveau, M. Vrac, and O. Mestre, 2013: Clustering of maxima: Spatial dependencies among heavy rainfall in France. J. Climate, 26, 7929-7937, https://doi.org/ 10.1175/JCLI-D-12-00836.1.

Besaw, L. E., D. M. Rizzo, M. Kline, K. L. Underwood, J. J. Doris, L. A. Morrissey, and K. Pelletier, 2009: Stream classification using hierarchical artificial neural networks: A fluvial hazard management tool. J. Hydrol., 373, 34-43, https://doi.org/10.1016/j.jhydrol.2009.04.007.

Burn, D. H., 1997: Catchment similarity for regional flood frequency analysis using seasonality measures. J. Hydrol., 202, 212-230, https://doi.org/10.1016/S0022-1694(97)00068-1.

Chang, F.-J., L.-C. Chang, and Y.-S. Wang, 2007: Enforced self-organizing map neural networks for river flood forecasting. Hydrol. Processes, 21, 741-749, https://doi.org/ 10.1002/hyp.6262.

Clark, D., 1994: Uncompahgre Project. Tech. Rep., U.S. Bureau of Reclamation, 20 pp., https://www.usbr.gov/projects/pdf. php?id=203.
De Michele, C., and R. Rosso, 2002: A multi-level approach to flood frequency regionalisation. Hydrol. Earth Syst. Sci., 6, 185-194, https://doi.org/10.5194/hess-6-185-2002.

Elliott, J. G., R. D. Jarrett, and J. L. Ebling, 1982: Annual snowmelt and rainfall peak-flow data on selected foothills region streams, South Platte River, Arkansas River, and Colorado River basins, Colorado. USGS Open-File Rep. 82-426, 90 pp., https://pubs.er. usgs.gov/publication/ofr82426.

Farsadnia, F., M. R. Kamrood, A. M. Nia, R. Modarres, M. Bray, D. Han, and J. Sadatinejad, 2014: Identification of homogeneous regions for regionalization of watersheds by two-level self-organizing feature maps. J. Hydrol., 509, 387-397, https:// doi.org/10.1016/j.jhydrol.2013.11.050.

Franks, S., C. White, and M. Gensen, 2015: Estimating extreme flood events-Assumptions, uncertainty and error. Proc. IAHS, 369, 31-36, https://doi.org/10.5194/piahs-369-31-2015.

Gupta, V. K., L. Duckstein, and R. Peebles, 1976: On the joint distribution of the largest flood and its time of occurrence. Water Resour. Res., 12, 295-304, https://doi.org/10.1029/ WR012i002p00295.

Hartigan, J. A., and M. A. Wong, 1979: Algorithm as 136: A $k$-means clustering algorithm. J. Roy. Stat. Soc., 28C, 100-108, https://doi.org/10.2307/2346830.

Hirschboeck, K. K., 1987: Hydroclimatically-defined mixed distributions in partial duration flood series. Hydrologic Frequency Modeling, V. P. Singh, Ed., Springer, 199-212, https://doi.org/ 10.1007/978-94-009-3953-0_13.

Homer, C. G., and Coauthors, 2015: Completion of the 2011 national land cover database for the conterminous United StatesRepresenting a decade of land cover change information. Photogramm. Eng. Remote Sens., 81 (5), 345-354.

Interagency Advisory Committee on Water Data, 1982: Guidelines for determining flood flow frequency. Bulletin 17B of the Hydrology Subcommittee, 183 pp., https://water.usgs.gov/osw/ bulletin17b/dl_flow.pdf.

Jain, S., and U. Lall, 2000: Magnitude and timing of annual maximum floods: Trends and large-scale climatic associations for the Blacksmith Fork River, Utah. Water Resour. Res., 36, 3641-3651, https://doi.org/10.1029/2000WR900183.

Jarrett, R. D., and J. E. Costa, 1988: Evaluation of the flood hydrology in the Colorado Front Range using precipitation, streamflow, and paleoflood data for the Big Thompson River basin. USGS Water-Resources Investigations Rep. 87-4117, 37 pp., https://doi.org/10.3133/wri874117.

Kalteh, A. M., P. Hjorth, and R. Berndtsson, 2008: Review of the self-organizing map (SOM) approach in water resources: Analysis, modelling and application. Environ. Modell. Software, 23, 835-845, https://doi.org/10.1016/j.envsoft.2007.10.001.

Kim, J.-S., S. Jain, and S. A. Norton, 2010: Streamflow variability and hydroclimatic change at the Bear Brook Watershed in Maine (BBWM), USA. Environ. Monit. Assess., 171, 47-58, https://doi.org/10.1007/s10661-010-1525-1.

Kohonen, T., 1990: The self-organizing map. Proc. IEEE, 78, 14641480, https://doi.org/10.1109/5.58325.

Lee, T., and C. Jeong, 2014: Frequency analysis of nonidentically distributed hydrometeorological extremes associated with large-scale climate variability applied to South Korea. J. Appl. Meteor. Climatol., 53, 1193-1212, https://doi.org/10.1175/JAMC-D-13-0200.1.

Likas, A., N. Vlassis, and J. J. Verbeek, 2003: The global $k$-means clustering algorithm. Pattern Recognit., 36, 451-461, https:// doi.org/10.1016/S0031-3203(02)00060-2.

Lin, G.-F., and L.-H. Chen, 2006: Identification of homogeneous regions for regional frequency analysis using the 
self-organizing map. J. Hydrol., 324, 1-9, https://doi.org/ 10.1016/j.jhydrol.2005.09.009.

Loukas, A., L. Vasiliades, and N. Dalezios, 2000: Flood producing mechanisms identification in southern British Columbia, Canada. J. Hydrol., 227, 218-235, https://doi. org/10.1016/S0022-1694(99)00182-1.

McCabe, G. J., Jr., and L. E. Hay, 1995: Hydrological effects of hypothetical climate change in the East River basin, Colorado, USA. Hydrol. Sci. J., 40, 303-318, https://doi.org/10.1080/ 02626669509491417.

Menne, M. J., I. Durre, R. S. Vose, B. E. Gleason, and T. G. Houston, 2012: An overview of the global historical climatology networkdaily database. J. Atmos. Oceanic Technol., 29, 897-910, https:// doi.org/10.1175/JTECH-D-11-00103.1.

Merz, R., and G. Blöschl, 2003: A process typology of regional floods. Water Resour. Res., 39, 1340, https://doi.org/10.1029/ 2002WR001952.

Nakamura, J., U. Lall, Y. Kushnir, A. W. Robertson, and R. Seager, 2013: Dynamical structure of extreme floods in the U.S. Midwest and the United Kingdom. J. Hydrometeor., 14, 485-504, https://doi.org/10.1175/JHM-D-12-059.1.

Parrett, C., A. Veilleux, J. Stedinger, N. Barth, D. L. Knifong, and J. Ferris, 2011: Regional skew for California, and flood frequency for selected sites in the Sacramento-San Joaquin River basin, based on data through water year 2006. USGS Scientific Investigations Rep. 2010-5260, 94 pp., https://pubs.usgs.gov/sir/2010/5260/.

Pizarro, G., and U. Lall, 2002: El Niño-induced flooding in the U.S. West: What can we expect? Eos, Trans. Amer. Geophys. Union, 83, 349-352, https://doi.org/10.1029/2002EO000255.

Pui, A., A. Lal, and A. Sharma, 2011: How does the Interdecadal Pacific Oscillation affect design floods in Australia? Water Resour. Res., 47, W05554, https://doi.org/10.1029/2010WR009420.

R Core Team, 2017: R: A Language and Environment for Statistical Computing. R Foundation for Statistical Computing, https://www.r-project.org/.
Sikorska, A. E., D. Viviroli, and J. Seibert, 2015: Flood-type classification in mountainous catchments using crisp and fuzzy decision trees. Water Resour. Res., 51, 7959-7976, https://oi.org/ 10.1002/2015WR017326.

Sivandran, G., 2002: Effect of rising water tables and climate change on annual and monthly flood frequencies. B. Eng. thesis, Centre for Water Research, University of Western Australia, 109 pp.

Smith, K. A., and A. Ng, 2003: Web page clustering using a selforganizing map of user navigation patterns. Decis. Support Syst., 35, 245-256, https://doi.org/10.1016/S0167-9236(02) 00109-4.

Srinivas, V., S. Tripathi, A. R. Rao, and R. S. Govindaraju, 2008: Regional flood frequency analysis by combining self-organizing feature map and fuzzy clustering. J. Hydrol., 348, 148-166, https:// doi.org/10.1016/j.jhydrol.2007.09.046.

Stucki, P., R. Rickli, S. Brönnimann, O. Martius, H. Wanner, D. Grebner, and J. Luterbacher, 2012: Weather patterns and hydro-climatological precursors of extreme floods in Switzerland since 1868. Meteor. Z., 21, 531-550, https://doi. org/10.1127/0941-2948/2012/368.

Sui, J., and G. Koehler, 2001: Rain-on-snow induced flood events in southern Germany. J. Hydrol., 252, 205-220, https://doi.org/ 10.1016/S0022-1694(01)00460-7.

Todhunter, P. E., 2012: Uncertainty of the assumptions required for estimating the regulatory flood: Red River of the north. J. Hydrol. Eng., 17, 1011-1020, https://doi.org/10.1061/(ASCE) HE.1943-5584.0000560.

Waylen, P. R., and M. Woo, 1982: Prediction of annual floods generated by mixed processes. Water Resour. Res., 18, 12831286, https://doi.org/10.1029/WR018i004p01283.

_ of precipitation and streamflow in the Aconcagua River basin, Chile. J. Hydrol., 120, 79-102, https://doi.org/10.1016/ 0022-1694(90)90143-L. 